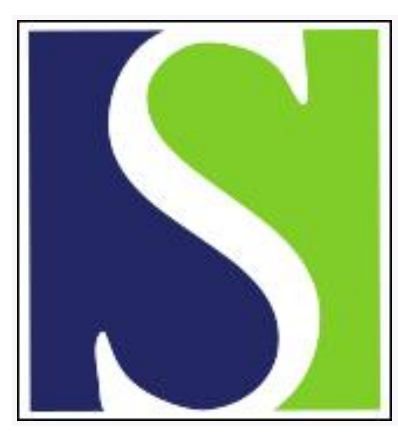

Scand J Work Environ Health 2000;26(3):237-242

https://doi.org/10.5271/sjweh.537

Issue date: Jun 2000

\title{
Sleep-disordered breathing and occupational accidents
}

by Ulfberg J, Carter N, Edling C

Key terms: arousal; attention; sleep apnea; snoring; sonorous breathing; unintentional injury

This article in PubMed: www.ncbi.nlm.nih.gov/pubmed/10901116

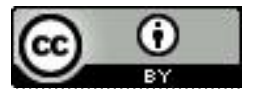




\title{
Sleep-disordered breathing and occupational accidents
}

\author{
by Jan Ulfberg, MD, ${ }^{1,2}$ Ned Carter, PhD, ${ }^{1}$ Christer Edling, $M D^{1}$
}

\begin{abstract}
Ulfberg J, Carter N, Edling C. Sleep-disordered breathing and occupational accidents. Scand J Work Environ Health 2000;26(3):237-242.
\end{abstract}

\begin{abstract}
Objectives The relationship between a common type of sleep disturbance, sleep-disordered breathing, and the risk of becoming involved in an occupational accident was studied.

Methods A 10-year retrospective comparison was made of occupational injuries reported to the Occupational Injury Statistics Division of the Swedish National Board of Occupational Safety and Health. The injury rates for 704 consecutive patients suffering from sleep-disordered breathing were compared with the rates for an employed, age-matched random sample of 580 subjects, drawn from the general population.

Results The risk of being involved in an occupational accident was about 2-fold among male heavy snorers and increased by $50 \%$ among men suffering from obstructive sleep apnea syndrome (OSAS). For females the risk increased by at least 3 -fold among heavy snorers and OSAS patients. Reduced vigilance and attention due to sleepdisordered breathing are the proposed mechanisms behind the results.

Conclusion The early identification and treatment of persons suffering from sleep-disordered breathing would not only have positive impact on individual health and well-being but also on occupational safety.
\end{abstract}

Key terms arousal, attention, sleep apnea, snoring, sonorous breathing, unintentional injury.

Occupational accidents continue to be a major social problem. Thousands of workers die in the United States annually due to occupational accidents and millions more are victims of nonfatal injuries (1). Even countries with relatively lower rates of occupational accidents, such as Sweden, find the human costs to be unacceptable and the economic costs to be in the billions of dollars each year (2). Among the many factors contributing to occupational injuries, some variables affecting worker arousal and attentiveness are known to be associated with increased injury risk. Alcohol, medications and shift work have, for example, all been implicated as contributors to occupational injuries $(3-8)$. However, little seems to be known about the influence of sleepiness (6) and sleep disturbance (9) on occupational accidents, although motor vehicle accidents are known to be more frequent among those suffering from sleep disturbances caused by sleep-disordered breathing $(10-14)$.

The prevalence of the severe form of sleep-disordered breathing, obstructive sleep apnea syndrome (OSAS) is high (15). Among middle-age Swedish men, the lowest prevalence of OSAS is reported to be $1.3 \%$ (16), and among American men the frequency of OSAS is estimated to be $4 \%(17)$. The less severe form of sleep-disordered breathing, snoring, is reported to be extremely prevalent, affecting $15-60 \%$ of the male population (18). Different investigations have found that excessive daytime sleepiness is a problem for $4-5 \%$ of the population in the Western world (19) and that it may be a consequence of sleep-disordered breathing $(15,20,21)$.

Heavy snorers may suffer from sleepiness as frequently as OSAS patients do and may experience substantially reduced self-perceived quality of life (22). The odds ratios for reporting sleepiness at work were found to be 30 -fold for OSAS patients and 10-fold for heavy snorers as compared with referents (21). The same study also found that OSAS and snoring patients showed increased odds ratios for measures of difficulties with concentration, learning new tasks, and performing monotonous tasks (21). The increased ventilatory effort seen in some heavy snorers during sleep may induce sleep fragmentation (23), and the microarousals associated with heavy snoring are hypothesized to reduce deep sleep (24).

This study used a case-referent design to evaluate the relationship between 2 types of sleep-disordered breathing, heavy snoring and OSAS, and the risk of being involved in an occupational accident. The Ethics Committee of the Faculty of Medicine, Uppsala University, and

1 Department of Medical Sciences/Occupational and Environmental Medicine, University Hospital, Uppsala, Sweden.

2 Sleep Disorders Center, Avesta Hospital, Avesta, Sweden.

Reprint requests to: Dr Jan Ulfberg, Department of Occupational and Environmental Medicine, University Hospital, SE-751 85 Uppsala, Sweden. [E-mail: jan.ulfberg@1tdalarna.se] 
the Swedish Data Inspection Board approved the study. All the subjects gave their informed consent to participate in the study.

\section{Subjects and methods}

The study was performed during a 3-year period. Data were collected from consecutive, heavy snoring, employed patients, aged $30-64$ years, who resided in Dalecarlia County. These patients, who complained of heavy snoring and excessive sleepiness, had been referred by their personal physician to the sleep laboratory of the Avesta Hospital in mid-Sweden for evaluation for suspected OSAS.

Prior to admission the patients (683 men and 163 women) responded to a questionnaire, which included questions about earlier and current occupation and current snoring habits. In order to determine the chronicity of snoring, we also asked the patients to describe their snoring habits during every 5 th year of their lifetime. Snoring frequency was assessed on the following 6-point scale: never, seldom, sometimes, rather often, nearly every night, every night. The responses "never", "seldom" and "sometimes" were classified as "nonsnoring", and "rather often", "nearly every night" and "every night" were classified as "snoring". In the patient group, 63 $(45 \%)$ of the women reported that they had snored $>10$ years. The corresponding figure among the male patients was $338(60 \%)$.

All the patients underwent sleep apnea screening, which included simultaneous nocturnal recording with a static-charge sensitive bed and oxymetry during a minimum of 4 hours of sleep. Minimum sleep time was determined from body movement, which has been shown to correlate well with polygraphically verified sleep times (25). The mattress of the static-charge sensitive bed allowed both breathing and body movements to be measured. When there is disordered breathing during sleep, one can record a special pathological breathing pattern, obstructive periodic breathing, which is measured as the percentage of total sleep time. Oxygen saturation was recorded with percutaneous oxymetry, and an oxygen desaturation index was defined as the average number of desaturations amounting to $\geq 4 \%$ per sleeping hour. Patients always have OSAS when obstructive periodic breathing exceeds $45 \%$ in combination with an oxygen desaturation index of $>6(25)$. This classification refers to the traditional definition proposed by Guilleminault et al (15) and has been found to be comparable to the polysomnographic method (25).

The patients never have OSAS when the amount of obstructive periodic breathing is $<18 \%$ and the oxygen desaturation index is $<2$, but they are diagnosed as heavy snorers. According to the clinical assessment, 338 men and 107 women were snorers and 225 men and 34 women suffered from OSAS. These patients made up the group used to determine the odds ratios. It was not possible to diagnose further the patients not fulfilling these criteria (periodic breathing $18-45 \%$ and oxygen desaturation index 2-6) with the sleep apnea screening method used. These 142 patients were classified as exhibiting borderline sleep-disordered breathing and were therefore excluded from this study. This group consisted of patients with a sleep disturbance related to impaired respiration of unspecified origin (ie, heavy snoring, OSAS and upper airway resistance syndrome (26).

No patient had received medical treatment, such as continuous positive airway pressure, during the course of the study. The use and effectiveness of nonprescription treatments for snoring was not known.

\section{Reference group}

Referents (479 men and 466 women in the age range $30-64$ years) were selected at random from the general population in the same county as the patients. This sample was obtained from a register maintained by the county tax authority that encompassed all county residents. The referents were mailed the same questionnaire as that received by the patients. After 1 and 2 months following the initial mailing, nonrespondents were sent reminders and an additional questionnaire. A group of 296 men and 294 women responded to the questionnaire. The response rate was $62 \%$. Altogether 6 women and 4 men in the reference group were retired, and these 10 persons were excluded from the analyses.

A random sample of 99 persons in this group underwent sleep apnea screening. On the basis of this sample, the estimated prevalence of heavy snoring was $20 \%$ for the men and $14 \%$ for the women; for OSAS the corresponding figures were $3.7 \%$ and $0.0 \%$, respectively (27).

A random sample of 75 (50 men and 25 women) of the nonrespondents in the reference group was contacted by telephone. All 75 reported that they had not responded because they did not believe that the questionnaire concerned them since they experienced no or insignificant sleep-related problems.

\section{Occupations and occupational accidents}

On the basis of questionnaire responses, all the subjects' current occupations were classified according to the Nordic Classification of Occupation (NYK 82), which is based on the International Standard Classification of Occupations (ISCO), with a few modifications (28). This classification was carried out by an experienced safety engineer, who was unaware of the purpose of the study and without information about the subjects' status as patient or referent. The distribution of types of occupations was similar for the 2 groups. Among the men, $24 \%$ of 
the referents and $23 \%$ of the patients were employed in the manufacturing sector. The corresponding figures for the women were $3 \%$ and $4 \%$, respectively. The distributions of patients and referents among blue- and whitecollar jobs were equivalent for both the men and the women.

Data concerning nonfatal occupational accident injuries for both the patient and reference groups were obtained for a 10-year period (1 November 1984 - 31 October 1994) from the Occupational Injury Statistics Division of the Swedish National Board of Occupational Safety and Health. The Injury Statistics Division compiles statistics on all occupational accidents and diseases in Sweden, including near accidents and injuries not requiring sick leave. Employer reporting of occupational accidents is mandatory. Only reports of traumatic accident injuries causing $\geq 1$ days of sick leave were included in the analyses. Thus acute overexertion injuries were excluded.

Further analyses were performed on all reported traumatic occupational accidents in which sleepiness or inattentiveness might have contributed, for example, falling due to stumbling and different kinds of contusions. Reports describing incidents related to acute injuries caused by explosions, the person being struck by a flying object or due to assault were excluded. Vehicle-related accidents were also excluded. Two men in the reference group, 2 male patients with OSAS, and 4 male snorers were reported having been injured due to a vehicle accident. None of the injuries among the female referents or patients were vehicle-related.

\section{Statistical analyses}

Logistic regression analysis was used to estimate the risk of the patients suffering an occupational accident, as approximated by the odds ratio, related to age. An odds ratio of $>1$ indicates that sleep-disordered breathing was positively related to occupational accidents. The logistic regression analyses were performed with the SPSS/PC+ computer program (SPSS Inc, Chicago, IL).

\section{Results}

Among the men in the reference group, 31 of 58 (53\%) accidents were related to assumed inattention. The corresponding figures among the female referents were 5 of $7(71 \%)$. The number of occupational accidents reported by the patients is shown in table 1 .

All the patient groups showed an increased risk of being involved in an occupational accident assumed to be due to inattention when compared with the reference groups (table 2). The adjusted odds ratio of the male heavy snorers being a victim of an occupational accident was 1.8 [95\% confidence interval (95\% CI) $1.1-2.8$ ]. The results indicate that the male OSAS patients showed a $50 \%$ increased risk of being injured in an occupational accident as compared with the male referents. The female patients (female heavy snorers and OSAS patients) showed a 4-fold increased risk of involvement in occupational accidents when compared with the referents. The odds of being traumatized by an occupational accident

Table 1. Reported occupational accidents over a 10-year period for male and female patients with sleep disordered breathing. (OSAS = obstructive sleep apnea syndrome)

\begin{tabular}{|c|c|c|c|c|c|c|}
\hline & \multicolumn{3}{|c|}{ Men } & \multicolumn{3}{|c|}{ Women } \\
\hline & $\begin{array}{l}\text { Diagnosed } \\
(N=563)\end{array}$ & $\begin{array}{l}\text { Total accidents } \\
\qquad(N=137)\end{array}$ & $\begin{array}{l}\text { Inattention accidents } \\
\qquad(\mathrm{N}=97)\end{array}$ & $\begin{array}{l}\text { Diagnosed } \\
(\mathrm{N}=141)\end{array}$ & $\begin{array}{l}\text { Total accidents } \\
\qquad(N=13)\end{array}$ & $\begin{array}{l}\text { Inattention accidents } \\
\qquad(\mathrm{N}=11)\end{array}$ \\
\hline OSAS & 225 & 44 & 36 & 34 & 5 & 5 \\
\hline Snorers & 338 & 93 & 61 & 107 & 8 & 6 \\
\hline
\end{tabular}

a Inattention accidents: all traumatic acute injuries requiring $\geq 1$ day's absence from work, except those resulting from vehicle accidents, explosions, being struck by flying objects or assault.

Table 2. Multivariate odds ratios (OR) and $95 \%$ confidence intervals $(95 \% \mathrm{Cl})$ for male and female patients' involvement in an occupational accident during a 10-year period due to inattention. ${ }^{a}$ (men: cases $=563$, OSAS $=225$, snorers $=338$ versus referents $=292$; women: cases $=141,0 S A S=34$, snorers $=107$ versus referents $=288,0 S A S=0$ obstructive sleep apnea syndrome)

\begin{tabular}{|c|c|c|c|c|c|c|}
\hline & \multicolumn{2}{|c|}{ Cases $^{b}$ versus referents } & \multicolumn{2}{|c|}{ OSAS versus referents } & \multicolumn{2}{|c|}{ Snorers versus referents } \\
\hline & $O R^{\circ}$ & $95 \% \mathrm{Cl}$ & $O R^{\circ}$ & $95 \% \mathrm{Cl}$ & $\mathrm{OR}^{\mathrm{c}}$ & $95 \% \mathrm{Cl}$ \\
\hline Men & 1.7 & $1.1-2.6$ & 1.5 & $0.9-2.6$ & 1.8 & $1.1-2.9$ \\
\hline Women & 4.3 & $1.5--12.6$ & 6.3 & $1.6-25.6$ & 3.3 & $0.98-11.0$ \\
\hline
\end{tabular}

a All acute injuries requiring $\geq 1$ day's absence from work, except those resulting from vehicle accidents, explosions, being struck by flying objects, or assault.

- All patients with sleep disordered breathing (OSAS and snorers)

c Odds ratios adjusted for differences in age. 
were almost 3-fold for the female heavy snorers and 6fold for the female OSAS patients.

\section{Discussion}

To our knowledge, this is the first study evaluating the relationship between sleep-disordered breathing and the risk of experiencing trauma due to an occupational accident. The results indicate that persons suffering from sleep-disordered breathing (OSAS and heavy snoring) do run an increased risk of becoming involved in an occupational accident. Reduced vigilance and attention due to sleep-disordered breathing are the proposed mechanisms behind the results. The finding of a positive relationship between sleep-disordered breathing and acute injury risk is consistent with findings from the traffic sector $(10-14)$. The results also agree with those demonstrating a relationship between factors that inhibit wakefulness and attention and increased injury rates (3-8).

Since sleep-disordered breathing is known to be associated with an increased rate of involvement in vehicle accidents, the reason for excluding such accidents from this study requires explanation. During the period under study, the register obtained by the Occupational Injury Statistics Division did not include accurate descriptions of the type of the vehicle involved. Moreover it was not possible to determine from the reports whether or not the injured person was a driver or a passenger. Consequently, the few accidents with vehicles involved were not included in the final analysis. However, it seems that vehicle accidents were more common among those with sleep-disordered breathing.

In this study selection bias may have influenced the response rate among the referents, which was rather low. There is a possible risk of an overestimation of sleep problems and accidents in the reference group as evidenced by the replies provided by the random sample of 75 nonrespondents, since they had not responded because they experienced no or insignificant sleep-related problems. Thus the reference group may have been "sleepier" than the whole population and, thereby, decreased the contrast between the 2 groups. Therefore, our estimations should be considered conservative.

There was no assessment of snoring habits in the reference group during every 5 th year of lifetime. Howev$\mathrm{er}$, we have previously reported the estimated prevalence of heavy snoring and OSAS in this sample of the general population (27) and assumed that the reference group included both snorers and nonsnorers. The inclusion of snorers in the reference group reduces the contrast between the cases and referents and leads to an underestimation of the true difference between the groups.
Our clinical experience indicates that patients diagnosed as suffering from OSAS have been heavy snorers and experienced symptoms for more than 10 years. This observation demonstrates one of the difficulties associated with conducting epidemiologic studies based on retrospective data. It is possible that the injury rate for OSAS patients was low due to selection bias. This patient category is known to report high work absenteeism $(29,30)$ and a "sick worker" effect may have occurred. OSAS patients may have been less frequently exposed to potential risks due to their work absences and, consequently, been less frequently involved in occupational accidents. Another possibility is that persons suffering from hypersomnolence have either voluntarily or involuntarily been placed in jobs with fewer risks within a given industry.

Obesity is a well-known risk factor for sleep-disturbed breathing, and obesity may possibly have been a confounder in this study. However, we did not treat body mass index as a confounder since we could find no evidence or indication in the literature that obesity is associated with increased injury risk in any setting. Our position is supported by the findings of Stoohs et al (31).

Despite the difficulties and confounding factors associated with retrospective studies, we believe that the problems connected with prospective studies are more serious. We do not believe that it would be ethically defensible to diagnose but fail to treat snoring or OSAS while monitoring the potential occurrence of an accident. While we are uncertain as to the exact length of time the patients met the criteria for an OSAS diagnosis, we also believe it unreasonable to assume that patients with diagnosed, but untreated, OSAS would maintain their occupational exposures for extended periods of time.

Occupational accidents due to trauma (excluding violence) are uncommon among women and few as compared with the rates of men. Although there were relatively more occupational accidents among the female patients as compared with the female referents, these results are uncertain due to the low numbers, as indicated by the broad confidence intervals. Snoring and OSAS as causes of excessive daytime sleepiness among women may go unrecognized. This lack of awareness may have influenced prevention efforts and may in part explain the large difference in accident likelihood between the men and women in this study.

The validity of the diagnostic methods we used is high (25). Using either a static-charge sensitive bed or oxymetry alone to diagnose OSAS gives a high sensitivity $(32,33)$. Using both produces a specificity of $100 \%$ for OSAS or snoring, according to a comparison with polysomnography (25). Polysomnography, the "golden standard" in clinical practice, is a method that is too cumbersome and costly to use in an investigation such as ours with a large number of patients. The screening method 
used in this study may, as occurred for us, produce a group of patients with borderline sleep-disordered breathing whose data cannot and should not be considered comparable.

The statistical analyses controlled for age, an important confounder. Although alcohol intake and alcohol dependence may influence accident risk, we did not control for them in the analyses since we had not requested information about intake throughout the study period. Current intake of alcohol was recorded, and this factor was not found to influence the findings.

In conclusion, this study indicates that patients with sleep-disordered breathing run an increased risk of becoming victims of occupational accidents. It seems likely that reduced vigilance and greater inattentiveness among these patients are the most likely explanations for the increased accident risk.

During recent years, effective treatments for both snoring and OSAS have been developed $(34,35)$ and these treatments have become more readily available. Early identification and treatment of snoring and OSAS could potentially reduce the number of occupational injuries, as well as improve the health and well-being of those identified.

\section{Acknowledgments}

The research described in this paper was supported by a grant from the Swedish Council for Work Life Research.

We thank Birgitta Nyström, Arne Lindberg, Mats Talbäck, and Jan Ifver for the assistance they provided during the study.

\section{References}

1. Baker SP, Conroy C, Johnston JJ. Occupational injury prevention. J Safety Res 1992;23:129_-33.

2. Jansson B, Springfeldt B. Samhällets kostnader för personskador [The costs of injuries to society]. In: Menckel $\mathrm{E}$ Kullinger B, editors. Femton års arbetsolycksfallsforskning i Sverige [Fifteen years of occupational accident research in Sweden]. Stockholm: Rådet för arbetslivsforskning, 1996:145-59.

3. Dawson DA. Heavy drinking and the risk of occupational injury. Accid Anal Prev 1994;26:655—65.

4. Gilmore TM, Alexander BH, Mueller BA, Rivara FP. Occupational injuries and medication use. Am J Ind Med 1996;30:234-9.

5. Smith L, Folkard S, Poole CJ. Increased injuries on night shift. Lancet 1994;344(8930):1137-9.

6. Åkerstedt T. Sleepiness as a consequence of shift work. Sleep 1988;11:17-34.

7. Åkerstedt T. Work hours and sleepiness. Neurophysiol Clin 1995;25:367-75.
8. Gold DR, Rogacz S, Bock N, Tosteson TD, Baum TM, Speizer FE, et al. Rotating shift work, sleep and accidents related to sleepiness in hospital nurses. Am J Public Health 1992; 82:1011-4.

9. Lavie P, Kremerman S, Wiel M. Sleep disorders and safety at work in industry workers. Accid Anal Prev 1982;14:311-4.

10. George CF, Nickerson PW, Hanly PJ, Millar TW, Kryger $\mathrm{MH}$. Sleep apnoea patients have more automobile accidents. Lancet 1987;2:447.

11. Findley LJ, Fabrizio M, Thommi G, Suratt PM. Severity of sleep apnea and automobile crashes. N Engl J Med 1989; 320:868-9.

12. Haraldsson P-O, Carenfelt C, Diderichsen F, Nygren $\AA$, Tingvall C. Clinical symptoms of sleep apnea syndrome and automobile accidents. ORL 1990;52:57-62.

13. Teran-Santos J, Jimenez-Gomez A, Cordero-Guevara J, and the cooperative group Burgos-Santander. The association between sleep apnea and the risk of traffic accidents. N Engl J Med 1999;340:847-51.

14. Suratt PM, Findley LJ. Driving with sleep apnea [editorial]. N Engl J Med 1999;340:881-3.

15. Guilleminault $C$, van der Hoed J, Mitler M. Clinical overview of the sleep apnea syndromes. In: Guilleminault C, Dement W, editors. Sleep apnea syndromes. New York (NY): AR Liss, 1978:1-12.

16. Gislason T, Almqvist M, Eriksson G, Taube A, Boman G. Prevalence of sleep apnea syndrome among Swedish men: an epidemiologic study. J Clin Epidemiol 1988;41:571—6.

17. Young T, Palta M, Dempsey J, Skatrud J, Weber S, Badr S. The occurrence of sleep-disordered breathing among middleaged adults. N Engl J Med 1993;328:1230 - 5.

18. Lugaresi E, Cirignotta F, Montagna P, Sforza E. Snoring: pathogenic, clinical and therapeutic aspects. In: Kryger $M$, Roth T, Dement W, editors. Principles and practice of sleep medicine. 2 ed. London: WB Saunders, 1994:621—9.

19. Bixler E, Kales A, Soldatos CR. Prevalence of sleep disorders in the Los Angeles metropolitan area. Am J Psychiatry 1979;136:1257-62.

20. Jansson C, Hillerdal G, Larsson L, Hultcrantz E, Lindholm C $\mathrm{E}$, Bengtsson $\mathrm{H}$, et al. Excessive daytime sleepiness and fatigue in nonapnoeic snorers: improvement after UPPP. Eur Respir J 1994;7:845-9.

21. Ulfberg J, Carter N, Talbäck M, Edling C. Excessive daytime sleepiness at work and subjective work performance in the general population and among heavy snorers and obstructive sleep apnea patients. Chest 1996;110:659-63.

22. Loth S, Petruson B, Wixén L, Wilhelmsen L. Evaluation of the quality of life of male snorers using the Nottingham Health Profile. Acta Otolaryngol (Stockholm) 1998;118:723-7.

23. Guilleminault C, Stoohs R, Duncan S. Daytime sleepiness in regular heavy snorers. Chest 1991;99:40-8.

24. Berg S, Nash S, Cole P, Hoffstein V. Arousals and nocturnal respiration in symptomatic snorers and nonsnorers. Sleep 1997;20:1157-61.

25. Svanborg E, Larsson H, Carlsson-Nordlander B, Pirskanen R. A limited diagnostic investigation for obstructive sleep apnea syndrome: oxymetry and static charge sensitive bed. Chest 1990;98:1342-5.

26. Guilleminault C, Stoohs R, Clerk A, Cetel M, Maistros P. A cause of excessive daytime sleepiness: the upper airway resistance syndrome. Chest 1993;104:781-7.

27. Ulfberg J, Carter N, Talbäck M, Edling C. Headache, snoring and sleep apnoea. J Neurol 1996;243:621-5.

28. National Swedish Labour Market Board. NYK 82, Nordic 
Standard Classification of Occupations. Stockholm: National Swedish Labour Market Board, 1983.

29. Kales A, Caldwell AB, Cadieux RJ, Vela-Bueno A, Ruch LG, Mayes SD. Severe obstructive sleep apnea-II: associated psychopathology and psychosocial consequences. J Chronic Dis 1985;38:427-34.

30. Servera E, Pérez M, Signes-Costa J, Ferris G, Rivera ML, Marin J. Changes in work absenteeism in patients with obstructive sleep apnea syndrome after treatment. Chest 1995;108 suppl 3:S162.

31. Stoohs RA, Guilleminault C, Itoi A, Dement WC. Traffic accidents in commercial long-haul truck drivers: the influence of sleep-disordered breathing and obesity. Sleep 1994;17:619-23

32. Polo O, Brissaud L, Sales B, Besset A, Billiard M. The validity of the static charge sensitive bed in detecting obstructive sleep apneas. Eur Respir J 1988;1:330-6.

33. Duchna HW, Rasche K, Orth M, Schultze-Werninghaus G. Sensitivitat und Spezifitat der Pulsoximetrie in der Diagnostik schlafbezogener Atmungstörungen. Pneumologie 1995;49 suppl 1:113-5.

34. Lowe A. Dental appliances for the treatment of snoring and obstructive sleep apnea. In: Kryger M, Roth T, Dement W, editors. Principles and practice of sleep medicine. 2 ed. London: WB Saunders, 1994:722-35.

35. Sullivan C, Berthon-Jones M, Issa F, Evers L. Reversal of obstructive sleep apnea by continuous positive airway pressure applied through the nares. Lancet 1981;1:862-5.

Received for publication: 6 April 1999 